\title{
¿Reformar sin gobernar? Desafíos institucionales de las policías en América Latina*
}

\author{
Lucía Dammert**
}

\begin{abstract}
RESUMEN
El incremento de la inseguridad y el crimen en América Latina han otorgado un rol central a la policía. Los logros son limitados y la percepción es crítica a la efectividad. Corrupción, abuso del uso de la fuerza, lentitud, e incluso apatia, son algunas de las caracteristicas que se atribuyen a las policías en prácticamente todos los paises de la región. El presente artículo revisa los procesos de reforma policial. Para ello, establece como eje articulador la capacidad de gobierno civil de las instituciones policiales: el interés y la posibilidad real por parte de funcionarios y actores gubernamentales de limitar la autonomía política de las policias, aumentar la transparencia, la rendición de cuentas y fortalecer la capacidad y efectividad institucional. Los resultados evidencian transformaciones claras que han fortalecido la autonomía burocrática, más que el efectivo control civil. Asi, se reforma bastante y se gobierna poco.
\end{abstract}

PALABRAS CLAVE

América Latina, policia, seguridad, crimen organizado.

\section{ABSTRACT}

The increase in insecurity and crime in Latin America has given the police a central role. Accomplishments are limited and perception is critical to effectiveness. Corruption, abuse of the use of force, slowness and even apathy are some of the characteristics attributed to the police work in practically all the countries of the region. This article reviews the processes of police reform. To this end, it establishes as an articulating axis the capacity of civilian government of the police institutions: the interest and the real possibility on the part of officials and governmental actors to limit the political autonomy of the police, increase transparency, accountability and strengthen the institutional capacity and effectiveness. The results show clear transformations that have strengthened bureaucratic autonomy more than effective civil control. It reforms a lot and governs little.

\section{KEYWORDS}

Latin America, police, security, organized crime.

*Artículo recibido el 10 de diciembre de 2017 y aceptado para su publicación el 3 de julio de 2018

*Profesora asociada en la Facultad de Humanidades de la Universidad de Santiago de Chile. (lucia.dammert@usach.cl) orcid.org/0000-0003-1239-4425 


\section{SUMARIO}

1. Introducción

2. La crisis de la seguridad

3. Control civil: marco analítico de lo militar a lo policial

4. Autonomía, opacidad y baja efectividad: las policías latinoamericanas

5. De las reformas y sus limitaciones

6. La capacidad y efectividad policial

7. Rendición de cuentas e iniciativas de integridad

8. Conclusiones

\section{Introducción}

El incremento de la inseguridad y el crimen en América Latina han otorgado un rol central a la policía para enfrentar la principal preocupación ciudadana. Los logros son limitados y la percepción de la efectividad de su labor es crítica. Corrupción, abuso del uso de la fuerza, lentitud e incluso apatía son algunas de las características que se atribuyen a las policías en prácticamente todos los países de la región.

En las últimas dos décadas, a partir de procesos internos, externos o gatillados por escándalos mediáticos, se han implementado múltiples iniciativas de reforma policial y han obtenido resultados mixtos o, directamente, fracasos. El análisis de estas iniciativas de reforma ha demostrado la capacidad real de cambio en diversas áreas del trabajo policial; modernización de sus procesos de reclutamiento y educación; aumento de la inversión pública; uso de tecnología; desarrollo de iniciativas de prevención del crimen, entre otros. Sin embargo, los hechos de corrupción individual e institucional, así como los de abuso del uso de la fuerza no han desaparecido.

El presente artículo revisa los procesos de reforma policial desde una óptica distinta, pues establece como eje la capacidad de gobierno civil de las instituciones policiales. Ésta se refiere al interés y posibilidad real de los funcionarios y actores gubernamentales para limitar la autonomía política de las policías, así como aumentar la transparencia, la rendición de cuentas y la capacidad y efectividad institucional.

El panorama no es alentador. Si bien se han logrado resultados positivos en diversos campos de la actividad policial, éstos no han transformado la cultura institucional ni aumentado los niveles de transparencia. Incluso aquellas instituciones que cuentan con la confianza ciudadana deben contar con 
mecanismos de rendición de cuentas fortalecidos, para evitar las actividades ilícitas que se desarrollan cuando no hay efectiva regulación.

La crisis de la política no es un terreno especialmente propicio para generar iniciativas de transparencia, anticorrupción y mayor efectividad. Sin embargo, ello no puede justificar que se siga avanzando sin cambios estructurales. Así, el artículo concluye con el reconocimiento de la necesidad de incluir la agenda de reforma policial dentro de la agenda política de reformas estructurales. El hecho de continuar con iniciativas parcializadas que ponen énfasis en mecanismos de mayor efectividad puede generar cambios. Éstos llegan a consolidar mayores niveles de autonomía burocrática, pero, en el largo plazo, continúan los problemas estructurales.

El artículo se organiza en cinco secciones. La primera analiza la crisis de la seguridad en América Latina, marcada por el aumento de la violencia, los homicidios y la sensación de inseguridad. Si bien existen diferencias nacionales, e incluso subnacionales, la seguridad se ubica entre los dos principales problemas de preocupación ciudadana. La segunda sección desarrolla el marco conceptual del estudio sobre el control civil basado en las relaciones cívicomilitares y su aplicación a los procesos de reforma policial. La tercera sección caracteriza a las organizaciones policiales latinoamericanas y su proceso de desarrollo de las últimas dos décadas. La cuarta sección expone los hallazgos basados en el análisis documental de múltiples procesos de reforma a las policías y más de cien entrevistas a especialistas, policías y actores políticos clave de la mayoría de países latinoamericanos en el periodo 2015-2017. La quinta sección propone conclusiones sobre la necesidad de continuar los procesos de reforma, pero con un énfasis más claro en la consolidación de control civil, para gobernar efectivamente un sector clave de las democracias latinoamericanas.

\section{La crisis de la seguridad}

Una de las principales preocupaciones de los latinoamericanos es la inseguridad. Si bien cada contexto nacional y subnacional tiene elementos distintos y, en muchos casos, no son comparables, la criminalidad se ha colocado como un desafío para el desarrollo y la calidad democrática en la región. Los problemas y magnitudes son diferentes. Así, por ejemplo, el gráfico 1 muestra la crítica situación regional respecto a los homicidios, pues supera el promedio mundial de 6 por cada 100000 habitantes. $^{1}$

\footnotetext{
${ }^{1}$ Igarapé, "Homicide Monitor", Igarapé Institute. [Consulta: 20 de noviembre, 2017]. Disponible en: https://homicide.
} 
El Salvador, Honduras, Jamaica y Venezuela se ubicaron entre los países con mayores tasas de inseguridad en el mundo, con niveles epidémicos de violencia armada, así como profundas consecuencias entre su población juvenil, que es víctima y victimaria principal de dicha violencia. ${ }^{2}$

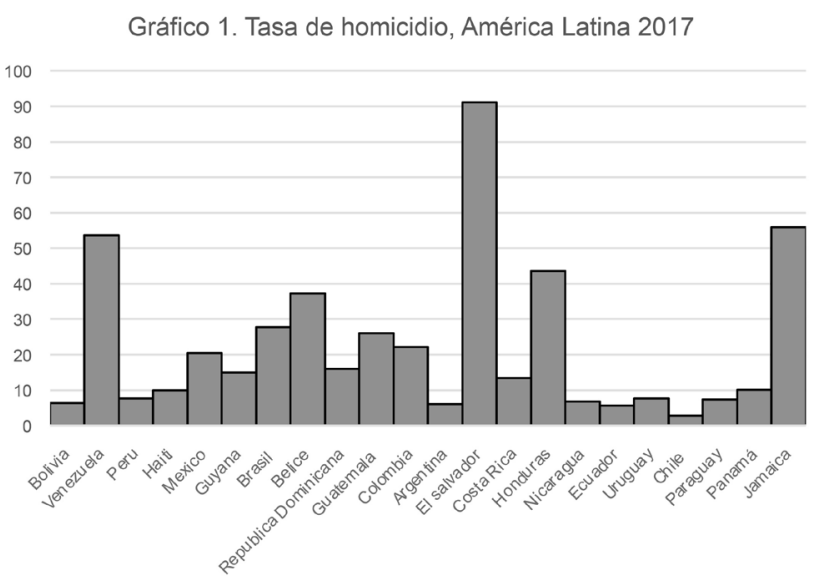

Fuente: Elaboración propia con base en Igarapé, "Homicide Monitor", Igarapé Institute. [Consulta: 20 de noviembre, 2017]. Disponible en: https://homicide.igarape.org.br/

Los homicidios evidencian altos niveles de uso de violencia que, en la región, está estrechamente vinculada con el tráfico de drogas. El aumento de la violencia es un fenómeno fundamental, sin embargo, concentrarse en este tipo de delito es mirar sólo una parte de la foto criminal. El siguiente gráfico presenta el porcentaje de ciudadanos que fueron víctimas de un delito en los últimos 12 meses para los años 2014 y 2016, ${ }^{3}$ periodo en el cual subió la incidencia.

Los promedios nacionales esconden realidades locales que deben ser resaltadas. Así, por ejemplo, Brasil, Argentina y México no aparecen entre los países con mayor victimización, pero el análisis por ciudad, e incluso por barrio, muestra la presencia de territorios que están actualmente gobernados por el crimen. Además de las diferencias territoriales, la especificidad delictual de los territorios permite afirmar que prácticamente todos los países enfrentan problemas de seguridad.

\footnotetext{
igarape.org.brl

${ }^{2}$ Cruz, José Miguel, "Police Misconduct and Political Legitimacy in Central America", Journal of Latin American Studies, vol. 47, núm. 2, pp. 251-283.

${ }^{3}$ Latin American Public Opinion Project, "The AmericasBarometer", Vanderbilt University. [Consulta: 20 de noviembre, 2017]. Disponible en: www.LapopSurveys.org
} 
Gráfico 2. Victimización, América Latina 2014-2016

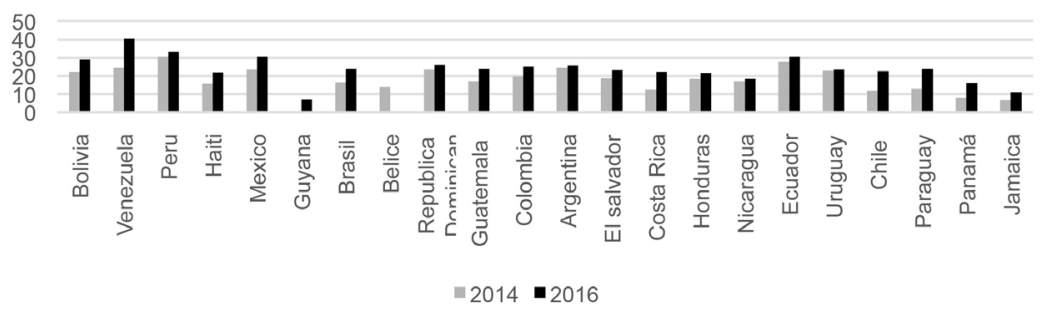

Fuente: Elaboración propia con base en LAPOP, 2017.

Más allá de las diferencias de magnitud de violencia, los latinoamericanos perciben que el crimen crece, el homicidio se generaliza y su seguridad se debilita. La preocupación se magnifica cuando la institución que debería estar dedicada a protegerlos, así como el sistema de justicia, que debería castigar a los criminales, son vistas como lentas, corruptas e ineficientes. La sensación de inseguridad y de impunidad son problemas que tienen impactos sociales, económicos y políticos. Aunque estos temas se han estudiado sólo tangencialmente, erosionan las bases mismas de los procesos democráticos. El gráfico 3 presenta los niveles de satisfacción con el accionar policial que en 12 países no superó $50 \%$ de la población. ${ }^{4}$

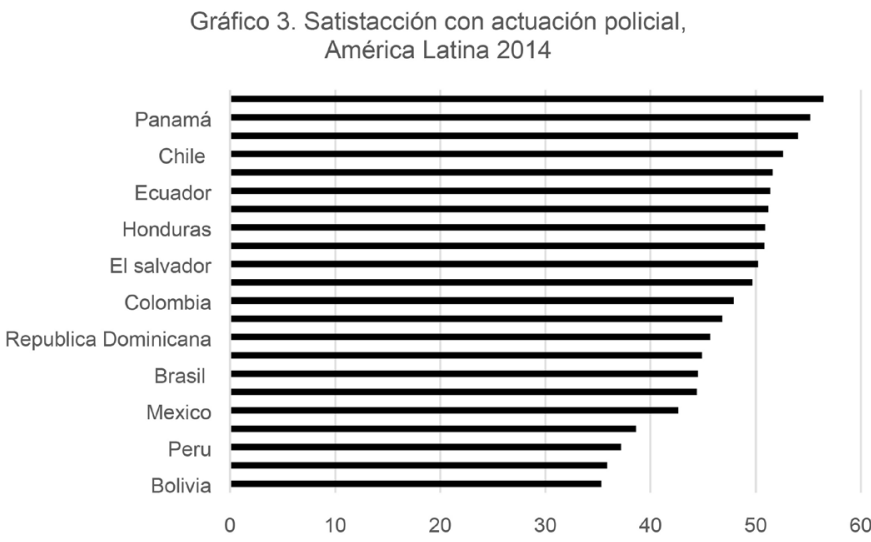

Fuente: Elaboración propia con base en Latin American Public Opinion Project, “The AmericasBarometer”, Vanderbilt University. [Consulta: 20 de noviembre, 2017]. Disponible en: www.LapopSurveys.org

\footnotetext{
${ }^{4}$ Latin American Public Opinion Project, "The AmericasBarometer", Vanderbilt University. [Consulta: 20 de noviembre, 2017]. Disponible en: www.LapopSurveys.org
} 
Los constantes e infructuosos procesos de cambio que han enfrentado las instituciones policiales en las últimas dos décadas han pavimentado el camino hacia la búsqueda de soluciones rápidas y efectivas. La militarización de la seguridad pública es ya una realidad en muchos países y, como se puede observar en el gráfico 4, ésta cuenta con aprobación ciudadana. Hacia el año 2014, más de $60 \%$ de la población apoyaba la idea de incluir a las fuerzas armadas en tareas de seguridad pública en todos los países, con la sola excepción de Chile y Uruguay.

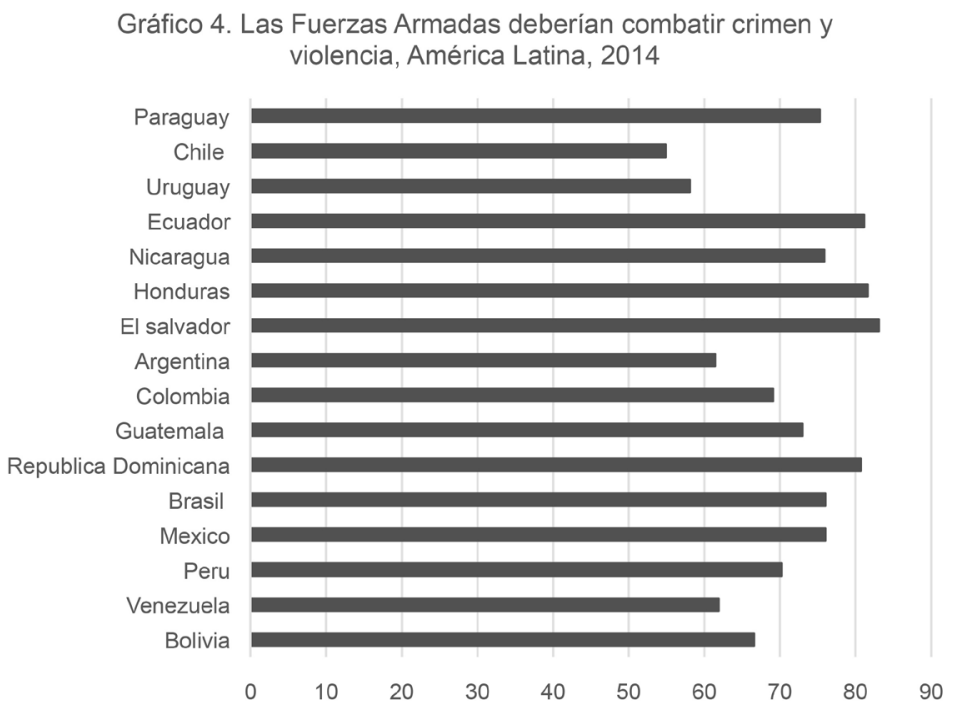

Fuente: Elaboración propia con base en Latin American Public Opinion Project, "The AmericasBarometer", Vanderbilt University. [Consulta: 20 de noviembre, 2017]. Disponible en: www.LapopSurveys.org

\section{Control civil: marco analítico de lo militar a lo policial}

En América Latina, el regreso de la democracia influyó en el desarrollo de una vasta literatura respecto al control civil sobre los militares. ${ }^{5}$ La principal preocupación analítica y política se instaló en la necesidad de dejar a los militares fuera de la actividad política, pues, por muchos años, ocuparon la región, dejando una amplia estela de violencia e impunidad. Desde el desarrollo teórico

\footnotetext{
${ }^{5}$ Trinkunas, HaRold, "Crafting Civilian Control in Emerging Democracies: Argentina and Venezuela", Journal of Interamerican Studies and World Affairs, vol. 42, núm. 3, pp. 77-109; Loveman, Brian, For La Patria: Politics and the Armed Forces America, Wilmington, Scholarly, 1999; Stepan, Alrened, Rethinking Military Politics: Brazil and the Southern Cone, Princeton, Princeton University Press, 1988.
} 
de Huntington, ${ }^{6}$ se reconoce que el problema del Estado moderno es la relación entre el militar experto y el político. Así, se instala la presencia de dos esferas separadas entre las cuales se producen situaciones claras de tensión. Uno de los principales problemas que enfrenta el análisis del control civil es la presencia de múltiples teorías parciales y débilmente conectadas que permiten el desarrollo de un cuerpo poco orgánico de investigación. ${ }^{7}$

Huntington $^{8}$ propone una clara diferenciación entre los fundamentos objetivos y subjetivos del control civil. El primero establece una clara delimitación de esferas de acción, así como un reconocimiento de la profesionalización militar; el segundo, más bien, refiere a la presencia de una visión común entre ambas esferas. El control civil objetivo logra sus metas cuando militariza lo militar y lo convierte en una herramienta del Estado. Mientras, el control subjetivo se logra cuando se "civiliza" a los militares. De esta forma, Huntington ${ }^{9}$ afirma que la esencia misma del control civil objetivo es el reconocimiento de la autonomía profesional militar.

Janowitz, ${ }^{10}$ por su parte, enfatiza en que el control civil subjetivo ocurre también cuando las fuerzas armadas quieren mantener "chequeado" al Gobierno. En este marco analítico, la mayor amenaza para el avance del control civil no son las características de las instituciones armadas, sino la estructura política e institucional de la sociedad. De igual manera, Pion-Berlin y Trinkunas ${ }^{11}$ definen que el elemento fundamental para identificar la capacidad del control civil no son los roles que tienen las instituciones armadas, sino quien los define como tales. De tal modo, enfatizan nuevamente en las capacidades de la sociedad para limitar el accionar institucional.

Bruneau $^{12}$ propone tres requisitos fundamentales para el desarrollo de control civil: a) capacidad institucional para efectivamente controlar las Fuerzas Armadas; b) capacidad de vigilancia para asegurar que los lineamientos

\footnotetext{
${ }^{6}$ Huntington, Samuel, The soldier and the State, Boston, Vintage Books, 1957.

${ }^{7}$ Albright, David, "Comparative Conceptualization of Civil-Military Relations", World Politics, vol. 32, núm. 4, pp. 553-576; Stepan, Alfred C. The Military in Politics: Changing Patterns in Brazil. Princeton, Princeton University Press, 1973.

${ }^{8}$ Huntington, Samuel, The soldier and the State, Boston, Vintage Books, 1957.

${ }^{9}$ Huntington, Samuel, The Strategic imperative: New policies for American security, Massachusets, Ballinger Publishing House, 1982.

${ }^{10}$ Janowitz, Morris, Military institutions and coercion in the developing nations, Chicago, The University of Chicago Press, 1977.

"Pion-Berlin, David y Trinkunas, Harold, "Democratization, Social Crisis, and the Impact of Military Domestic Roles in Latin America", Journal of Political and Military Sociology, vol. 33, núm. 1, pp. 5-24.

${ }^{12}$ Bruneau, Thomas, "Civilians and the Military in Latin America: The Absence of Incentives", Latin American Politics and Society, vol. 55, núm. 4, pp. 143-160.
} 
civiles sean realizados, y c) reforma del contenido y forma de la educación militar. Así, las diversas definiciones y conceptualizaciones sobre control civil comparten dos elementos centrales, vinculados con la presencia de autoridad, para tomar decisiones, y la capacidad de vigilancia, para asegurar que las decisiones se cumplan. ${ }^{13}$ Esto significa que los civiles deben tomar las decisiones fundamentales vinculadas con la seguridad en las sociedades, incluso cuando no tienen experticias técnicas relevantes. ${ }^{14}$

Si bien la mayoría de los países latinoamericanos cuenta con procesos de elección democrática constantes, la calidad de la democracia sigue en cuestionamiento. ${ }^{15}$ En el sector seguridad, se puede identificar un cambio sustancial vinculado con la disminución de la preocupación por la participación militar en la política contingente ${ }^{16} \mathrm{y}$ un aumento de la preocupación por el rol de las instituciones policiales en enfrentar la inseguridad. ${ }^{17}$

El debate teórico acerca del control civil sobre las policías ha sido limitado. Si bien múltiples son los análisis de caso o propuestas de política que acentúan la necesidad de un efectivo marco de control civil sobre el trabajo policial, estas propuestas carecen de un marco analítico común. ${ }^{18}$ El presente artículo retoma la perspectiva analítica utilizada para las relaciones cívico-militares, reconociendo la necesidad de gobernar a las instituciones que mantienen el monopolio del uso de la fuerza. Retomando a Janowitz, ${ }^{19}$ pero desde una perspectiva policial, profesionalizar el trabajo policial (control civil objetivo) y hacerlo más abierto al mundo civil (control civil subjetivo) no deberían ser mecanismos contradictorios, sino complementarios.

Cuando se analiza el trabajo policial, control civil y profesionalización son dos conceptos elusivos. La literatura anglosajona desarrolla múltiples análisis sobre el trabajo policial y enfatiza en el segundo concepto, dado que son limitados los casos de alta autonomía policial, autodefinición de políticas y

\footnotetext{
${ }^{13}$ Feaver, Peter, Armed Servants: Agency, Oversight, and Civil-Military Relations, Boston, Harvard University Press, 2003. ${ }^{14}$ Feaver, Peter, "The civil-military problematique: Huntington, Janowitz, and the question of civilian control", Armed Forces \& Society, vol. 23, núm. 2, 1996, pp. 149-178;

${ }^{15}$ Perez Liñan, Anibal \& Smith, Noah, "Democratic quality and democratic survival", en Luca Tomini y Giulia Sandri (eds.), Challenges of Democracy in the 21st Century. Concepts, Methods, Causality and the Quality of Democracy, Nueva York, Routledge, 2018.

${ }^{16}$ Pion-Berlin, David y Martinez, Rafael, Soldiers, politicians, and civilians: Reforming civil-military relation in Democratic Latin America, Cambridge, Cambridge University Press, 2017.

${ }^{17}$ Mota-Prado, Mariana, Trebilcock, Michael y Hartford, Patrick, "Police Reform in Violent Democracies in Latin America", Hague Journal on the Rule of Law, vol. 4, núm. 2, pp. 252-85.

${ }^{18}$ Arias, Patricia, Rosada-Granados, Héctor y Sain, Marcelo Fabiàn, Reformas policiales en América Latina. Principios y lineamientos progresistas, Bogotá, FES, 2012.

${ }^{19}$ JAnowitz, MorRIS, The new military changing patterns of organization, Bussel Saga Foundation, New York, 1964.
} 
opacidad. Tal situación recalca en la necesidad de un marco analítico para la particularidad del trabajo policial en América Latina.

Ahora bien, la profesionalización policial se puede analizar al menos de cuatro formas: a) altas expectativas sobre el trabajo policial desarrollado con un estándar de resolución de problemas, trato ciudadano y efectividad significativo; b) autorregulación, entendida como capacidad de independencia operacional para el logro de los objetivos; c) experticia y conocimiento como elementos fundantes del trabajo policial, alejándolo del sentido común, y d) normas internalizadas que permiten el desarrollo de una labor clara, sin necesidad de vigilancia externa o fuertes estructuras burocráticas de seguimiento. ${ }^{20}$

Si bien las anteriores no son categorías excluyentes, marcan un punto de inicio sobre el rol que en cada uno de estos ámbitos juega el control civil. Por otra parte, en todos los casos, éste tiene un rol secundario. Así, la literatura policial pondría mayor énfasis en el control civil objetivo, instalando mecanismos o espacios donde se realiza una directa relación con la comunidad o con las autoridades políticas. ${ }^{21}$

En América Latina, las instituciones policiales jugaron roles clave en el mantenimiento de las dictaduras militares, las guerras civiles y, en general, en el apoyo al poder político de las clases dominantes. ${ }^{22}$ Desde esta perspectiva, se propone un marco analítico específico para analizar los procesos de reforma policial, considerando el fortalecimiento del control civil como un derrotero ineludible. Los ejes de análisis son, por un lado, la capacidad y efectividad policial entendida como las funciones y misiones que tienen las instituciones, así como los mecanismos por los cuales se definen. Por otro lado, la rendición de cuentas como indicador de transparencia y capacidad de vigilancia sobre las acciones que realizan las instituciones policiales (véase figura 1).

De esta forma, los procesos de reforma policial deberían tener como meta el aumento de la capacidad y efectividad policial, así como de la rendición de cuentas y la transparencia institucional, para lograr un control civil efectivo. Sin embargo, se presenta también otro contexto que llamamos control civil reactivo o aquel que se presenta en instituciones con incrementales mecanismos de rendición de cuentas, pero bajos grados de efectividad o capacidad policial. Por otro

\footnotetext{
${ }^{20}$ SLANSKY, DAVID, "The promise and the perils of police professionalism" en Jennifer Brown (ed.), The future of policing, Nueva York, Routledge, 2014.

${ }^{21}$ Brogden, Michael, The police: Autonomy and consent, Londres, Academic Press, 1982.

22 Arias Desmond, Enrioue y Goldstein, Daniel, Violent Democracies in Latin America, Durham, Duke University Press, 2010. Brinks, Daniel, The judicial response to police killings in Latin America: Inequality and the rule of law, Nueva York, Cambridge University Press, 2016.
} 
lado, las instituciones más opacas y con bajos niveles de rendición de cuentas pueden a su vez tener altos niveles de efectividad, consolidando un modelo de acción que llamamos de autonomía burocrática o de bajos niveles de efectividad a los cuales llamaremos "de autonomía disfuncional".

Figura 1. Marco analítico control civil / autonomía policial

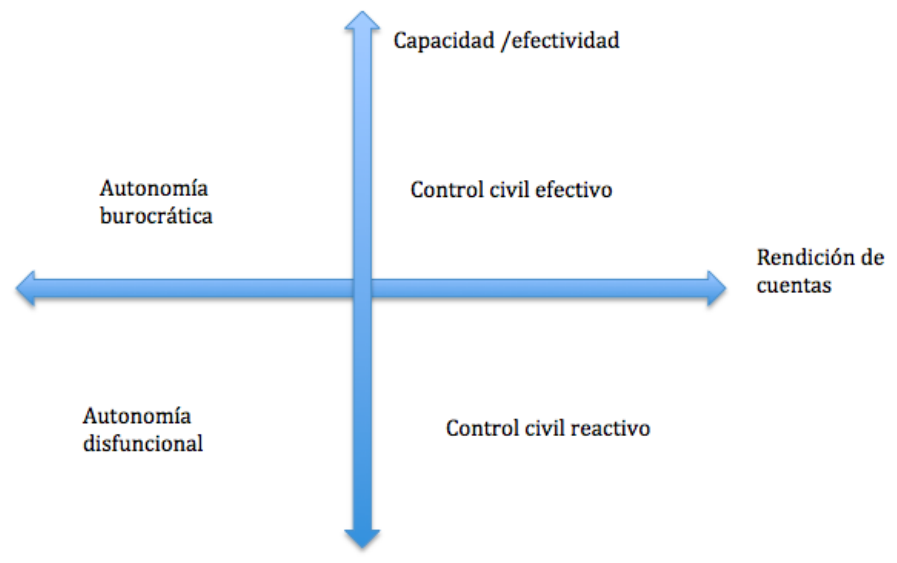

Fuente: Elaboración propia, 2018.

A continuación, se analiza la realidad policial en los países de América, así como los diferentes procesos de reforma que se han realizado en las últimas dos décadas. De tal modo, se busca identificar los vacíos y temas pendientes hacia la consolidación de un trabajo policial con control civil efectivo.

\section{Autonomía, opacidad y baja efectividad: las policías latinoamericanas}

Desde inicios de los años ochenta, las policías empezaron a jugar un rol cada vez más importante para las frágiles democracias latinoamericanas. ${ }^{23} \mathrm{El}$ fin de las dictaduras y guerras civiles puso a instituciones tradicionalmente secundarias en la estructura del gobierno, en un rol medular: entregar seguridad a los ciudadanos. Casi de un día para otro, pasaron de ser órganos partícipes de la violencia política o cuidadores de los privilegios a encargados de la seguridad y parte de la administración de justicia.

${ }^{23}$ Dammert, LuciA, Fear and Crime in Latin America: Redefining State-Society Relations, Nueva York, Routledge, 2012. 
Los procesos de reforma del sector seguridad se concentraron en consolidar la salida de las Fuerzas Armadas de las decisiones políticas. En Centroamérica, parte de los acuerdos de paz incluyeron la creación de nuevas instituciones policiales que alejaran el fantasma de las violaciones de derechos humanos y establecieran misiones vinculadas con la seguridad pública y la protección de los ciudadanos. ${ }^{24}$ En el resto de la región, los procesos de cambio en las instituciones policiales se realizaron posteriormente, y en el marco de iniciativas específicas. Por otro lado, en los años noventa se avanzó en la necesidad de reformar el procedimiento penal, sin embargo, en la mayoría de los países, esta transformación ha enfrentado significativos desafíos. ${ }^{25}$

En la región, no existe un único modelo policial. Algunos países tienen cuerpos policiales nacionales que cumplen con todas las tareas vinculadas a la prevención y el control (Perú, Uruguay, Ecuador, El Salvador y Honduras). Otros, de organización federal, cuentan con instituciones regionales (Argentina y Venezuela), e incluso locales (México y Brasil). En su interior, cada una de estas instituciones enfrenta definiciones de misión y funciones variadas que dificultan su comparación. Sin embargo, prácticamente todas comparten altos niveles de desconfianza ciudadana, vinculada con bajos niveles de efectividad, crecientes niveles de corrupción y uso excesivo de la fuerza. ${ }^{26}$

Desde inicios de los años noventa, los procesos que han impactado a todos los países de la región son el aumento de la preocupación por el crimen callejero y la creciente presencia del crimen organizado. ${ }^{27}$ La carencia de información rigurosa previa a esa década limita la comparación longitudinal sobre la magnitud del fenómeno criminal cotidiano. Pero, en aquellos países donde se realizan encuestas de opinión pública, la inseguridad -que incluye la presencia de tráfico de drogas- se ubica entre las principales preocupaciones de sus ciudadanos.

El sector seguridad, conformado por las policías, la justicia y el sistema carcelario, no tuvo capacidad real para enfrentar estos cambios y se instaló

\footnotetext{
${ }^{24}$ Cruz, José Miguel, "Police Misconduct and Political Legitimacy in Central America", Journal of Latin American Studies, vol. 47, núm. 2, pp. 251-283.

${ }^{25}$ UngaR, MARK, "The Rot Within: Security and Corruption in Latin America", Social Research: An International Quarterly, vol. 80, núm. 4, pp. 1187-1212. PASARA, LuIs, "International support for justice reform: Is it worthwhile?", Mexican Law Review, vol. 6, núm. 1, pp. 75-118.

${ }^{26}$ BobeA, LuLIAN, "The emergence of the democratic citizen security policy in the Dominican Republic", Policing and Society, vol. 22, núm. 1, pp. 57-75.

${ }^{27}$ Lagos, Marta, Dammert, Lucía, La Seguridad Ciudadana: El Problema Principal De América. [Consulta: 27 de octubre, 2017]. Disponible en: http://www.latinobarometro.org/documentos/LATBD_La_seguridad_ciudadana.pdf
} 
en un círculo vicioso marcado por altos niveles de autonomía y opacidad, así como por bajos niveles de efectividad. ${ }^{28}$

Parte sustancial del trabajo policial no se relaciona con el crimen. De hecho, su accionar a nivel local, la relación con la comunidad, la definición de prioridad de servicios y el establecimiento de mecanismos de interacción se definen día a día en diversas instancias internas no relacionadas con tareas de prevención o control del delito. Todo lo anterior podría ser considerado autonomía profesional, pero es deseable que las instituciones enfrenten nuevos desafíos con creatividad y eficiencia. ${ }^{29}$ No obstante, en América Latina, el marco de interpretación del tema policial es particular. Se debe asumir que las instituciones han consolidado importantes niveles de autonomía política y que ésta les permite avanzar con base en el uso excesivo de la fuerza ${ }^{30}$ o discrecionalidad para definir cambios estructurales dentro de la organización. ${ }^{31}$

Una mayor autonomía policial tiene como contracara menor poder de los gobiernos para controlar efectivamente a las fuerzas de orden. Esta situación se desarrolla por dos procesos distintos. Por un lado, el poder político deja de lado su capacidad de ejercicio del control policial y "deja hacer", esperando que los resultados sean positivos. Cuando no se logran los resultados esperados, la solución es el cambio abrupto de un jefe policial o del mando institucional. ${ }^{32}$ Por otro lado, el poder político alienta la capacidad policial con altos niveles de autonomía, considerando que estos cuerpos son los verdaderos encargados de brindar seguridad a los ciudadanos. En este caso, cuando los resultados son negativos o se descubren escándalos de abuso o corrupción, los mismos tienden a ser encubiertos o incluso justificados. ${ }^{33}$

\footnotetext{
${ }^{28}$ Mota-Prado, Mariana, Trebilcock, Michael y Hartford, Patrick, "Police Reform in Violent Democracies in Latin America", Hague Journal on the Rule of Law, vol. 4, núm. 2, pp. 252-285. Sozzo, MÁxımo, "Policing after Dictatorship in South America", en Ben Bradford, Beatrice Jauregui, Ian Loader, Jonny Steinberg (eds.), The sage Handook of Gobal Policing, Londres, SAGE, 2016, pp. 337-355.

${ }^{29}$ ReINER, Robert, The politics of the police, Hemel Hempstead, Harvester Wheatsheaf, 1992.

${ }^{30}$ Ruiz Torres, Miguel y Azaola Garrido, Elena, "Cuadrar el delito: Corrupción institucional y participación de policías en el secuestro en México", Perfiles Latinoamericanos, vol. 22, num. 4, pp. 91-112. Hinton, Mercedes, The State on the Streets. Police and Politics in Argentina and Brazil, Denver, Lynne Rienner, 2006.

${ }^{31}$ HathazY, Paul, "Fighting for a democratic police: Politics, Experts and Bureaucrats in the transformation of the police in post-authoritarian Chile and Argentina", Comparative Sociology, núm. 12, pp. 1-43.

32 Dammert, Lucie, "The Peruvian Perfect Storm: State Fragility, Corruption and Organized Crime", en H. Kassab \&t Jonathan Rosen (eds.), Fragile States in the Americas, Washington, Lexington Books, 2016, pp. 78-101; SAin, MArcelo Fabián, El Leviatán azul. Policía y Política en la Argentina, Buenos Aires, Siglo XXI, 2008; Seri, Guillermina, Seguridad: Crime, Police Power, and Democracy in Argentina, Nueva York, Continuum International Publishing Group, 2012.

${ }^{33}$ Antillano, Andrés, "Crimen y castigo en la revolución bolivariana", Cuestiones de Sociología, núm. 10. [Consulta: 26 de noviembre, 2017]. Disponible en: http://www.cuestionessociologia.fahce.un/p.edu.ar/article/view/CSn10a19/6096
} 
Otra característica del trabajo policial en América Latina es la opacidad. Si bien, en los últimos años, se han hecho esfuerzos por difundir su accionar, a través de los medios de comunicación masiva, e incluso de las redes sociales, aún se desconoce mucha información básica. Los mecanismos de rendición de cuentas son débiles, se entrega información pocas veces certera y con amplios espacios de discrecionalidad. La mayoría de las instituciones, especialmente aquellas de carácter militar, no entregan información sobre mecanismos de formación y entrenamiento; mecanismos de desarrollo de carrera, disposiciones para la rotación de personal; distribución de personal, entre otras muchas áreas de limitada transparencia.

La administración financiera también es una incógnita que se responde con información general, sin explicar las grandes inversiones públicas que se han desarrollado en los últimos años. Opacidad administrativa y altos niveles de autonomía son una receta de especial peligrosidad para asociaciones ilícitas que utilizan dineros públicos en busca de beneficios privados. ${ }^{34}$ Finalmente, en la relación con otras instituciones del sector seguridad, se profundiza el desconocimiento, e incluso la competencia. ${ }^{35}$

Tal vez el principal elemento que impacta en la evaluación ciudadana sobre el accionar policial es su baja efectividad. La percepción generalizada de los ciudadanos es que los delincuentes desarrollan carreras fructíferas principalmente por la incapacidad policial. La información disponible así lo corrobora. Los indicadores de efectividad del trabajo policial son antiguos y se siguen vinculando con cantidad de detenidos o droga decomisada, a pesar de la vasta literatura que explicita la poca relevancia de ambos guarismos. La multiplicidad de situaciones que enfrenta la policía de forma cotidiana requiere de mecanismos de innovación, basados en un proceso de descentralización de la toma de decisiones y de evaluación permanente.

Este panorama institucional ha permitido el desarrollo de la corrupción generalizada. Ésta se puede apreciar en hechos cotidianos de soborno o en ámbitos institucionales vinculados con la penetración del crimen organizado o la mala utilización de los dineros públicos. ${ }^{36}$ Por ejemplo, el último informe de

\footnotetext{
${ }^{34}$ La investigación judicial está en proceso al momento de escribir el presente artículo. Para mayor detalle véase: http://ciperchile.cl/2017/03/16/corrupcion-en-carabineros-las-mas-de-40-alertas-que-nadie-quiso-escuchar/

35 PASARA, LuIs, "International support for justice reform: Is it worthwhile?", Mexican Law Review, vol. 6, núm. 1, pp. 75-118.

${ }^{36}$ Corbacho, Ana, Jula, Phillpp y Ruiz-Vega, Mauricio, "Crime and Erosion of trust: Evidence for Latin America", World Development, núm. 70, pp. 400-415. Dudley, Steven, "How drug trafficking operates, corrupts in Central America", Insight Crime, julio, 2016. [Consulta: 17 de septiembre, 2017]. Disponible en: http://www.insightcrime.org/ news-analysis/how-drug-trafficking-operates-corrupts-in-central-america
} 
Transparencia Internacional mostró que la policía era considerada como una de las instituciones más corruptas en México, Bolivia y Venezuela. ${ }^{37}$ Es más, una encuesta nacional de victimización implementada en Brasil en 2013 arrojó que $7.2 \%$ de los ciudadanos de Río de Janeiro han sido víctimas de corrupción policial. ${ }^{38}$

En muchos países, la corrupción es una práctica sistemática, estrechamente vinculada con actividades del crimen organizado. ${ }^{39}$ En Perú, existe evidencia sobre oficiales de policía ubicados en áreas estratégicas de la Amazonía que protegen el desarrollo de la minería ilegal y el narcotráfico. También en Argentina, en los últimos veinte años, los escándalos de corrupción político-policial han sido cotidianos, con ramificaciones que van desde la administración del juego y la prostitución a nivel local hasta la vinculación con el narcotráfico y actividades de lavado de activos. ${ }^{40}$

El área más violenta de la región, el triángulo norte en Centroamérica (Guatemala, Honduras y El Salvador), está lleno de casos de participación policial en actividades criminales, incluso asesinatos para proteger a cárteles de drogas. ${ }^{41}$ Desafortunadamente, no son situaciones aisladas, sino un marco general de actividades policiales que develan el estrecho vínculo entre actividades criminales, redes políticas y accionar policial.

El excesivo uso de la fuerza es otro elemento cotidiano del trabajo policial. En Brasil, la situación ha alcanzado situaciones críticas; sólo en Río de Janeiro, durante el año 2015, más de 640 personas murieron a manos de oficiales de policía en servicio. ${ }^{42}$ Aún más, en Venezuela, el ministro de Justicia, durante el primer semestre de 2010, afirmó que " $20 \%$ del total de crímenes violentos fueron cometidos por la policía”. ${ }^{43}$ Para el caso de Argentina, Glanc ${ }^{44}$ relaciona directamente la violencia policial contemporánea con las experiencias

\footnotetext{
${ }^{37}$ Transparencia Internacional, Corruption Perceptions Index 2015, Transparencia Internacional. [Consulta: 10 de septiembre, 2017]. Disponible en: http://www.transparency.org/cpi2015

${ }^{38}$ Crisp \& Datafolha, Pesquisa Nacional de Victimizaçao 2013. Sumário Executivo. [Consulta: 27 de octubre, 2017]. Disponible en: http://www.interconect.com.br/clientes/pontes/blog/pnv.pdf

${ }^{39}$ UnODC, Transnational organized crime in Central America and the Caribbean. A threat assessment, Viena, unODC, 2012.

${ }^{40}$ Sain, Marcelo Fabián, "Es la política, estúpido. El Gobierno Federal frente a la reforma policial en Argentina", Comunes, núm. 1, pp. 35-64.

${ }^{41}$ Bruneau, Thomas, Dammert, Lucia y Skinner, Elzabeth, Maras: Gang Violence and Security in Central America, Austin, University of Texas Press, 2011.

${ }^{42}$ Human Rights Watch, "World Report 2016", Human Rights Watch. [Consulta: 20 de noviembre, 2017]. Disponible en: https://www.hrw.org/sites/default/files/world_report_download/wr2016_web.pdf

${ }^{43}$ CARRoll, RoRY, "Deadly force: Venezuela's police have become a law unto themselves", The Guardian. [Consulta: 28 de octubre, 2017]. Disponible en: https:/www.theguardian.com/world/2009/sep/06/venezuela-police-law-themselves ${ }^{44}$ Glanc, LaURA, "Caught between soldiers and police officers: police violence in contemporary Argentina", Policing and Society, vol. 24, núm. 4, pp. 479-496.
} 
dictatoriales pasadas. Explica que lo anterior ha dejado poco espacio para cambios relevantes en esta área a partir de las experiencias de reforma.

De hecho, desde el retorno de la democracia electoral en Argentina, más de 3390 personas han sido asesinadas por la policía. ${ }^{45}$ Finalmente, el aumento de la conflictividad social desafía a los oficiales de policía a responder con estrategias no violentas. Desafortunadamente, la evidencia muestra que no ha sido el caso en países como Chile o Venezuela, donde la policía se ha distinguido por su excesivo uso de la fuerza al enfrentar las protestas sociales.

Todo lo anterior ha erosionado los pilares de la legitimidad policial. En consecuencia, se han consolidado nuevos actores que buscan responder a las necesidades ciudadanas. Entre estos actores se incluyen la seguridad privada y las organizaciones comunitarias que desarrollan actividades tradicionalmente vinculadas con la labor policial, como las rondas, o mecanismos de autoprotección. ${ }^{46}$

En América Latina, la ansiedad ciudadana vinculada a los elementos explicitados han sido los disparadores de procesos de reforma policial en las últimas dos décadas. En contraste con la realidad anglosajona, donde estos procesos se desarrollaron inicialmente "por el deseo del gobierno conservador en turno de lograr un mayor control y disciplina financiera" ${ }^{47}$ en América Latina, lejos de retroceder, la inversión pública en policías ha aumentado en prácticamente todos los países. ${ }^{48}$

\section{De las reformas y sus limitaciones}

Reformar la policía es una tarea especialmente compleja. ${ }^{49}$ En América Latina, "el proceso de reforma policial es una tarea notoriamente difícil y laboriosa, en parte por las contradicciones inherentes entre el rol de la policía y los ideales de la democracia”. ${ }^{50} \mathrm{Al}$ analizar la experiencia argentina, Saín afirma que "reformar la policía implica reformar la política, de hecho, cambiar los caminos

\footnotetext{
${ }^{45}$ Seri, Guilermina, Seguridad: Crime, Police Power, and Democracy in Argentina, Nueva York, Continuum International Publishing Group, 2012.

${ }^{46}$ Dammert, Lucia y Salazar, Felipe, ¿Duros con el delito? Populismo e inseguridad en América Latina, Santiago de Chile, Flacso, 2009. UngaR, MARK, "The Privatization of Citizen Security in Latin America: From Elite Guards to Neighborhood Vigilantes", Social Justice, núm. 34, pp. 20-37.

${ }^{47}$ Sharp, Douglas, "Who needs theories in policing? An introduction to a special issue on policing", The Howard Journal, vol. 44, núm. 5, p. 453-455.

${ }^{48}$ Jattman, Laura, The costs of crime and violence: New evidence and insights in Latin America and the Caribbean. [Consulta: 18 de octubre, 2017]. Disponible en: https://publications.iadb.org/handle/11319/8133\#sthash.VUbnzmll.pdf ${ }^{49}$ Dammert, Lucia, "Challenges of police reform in Latin America", en R. Sieder, K. Ansolabehere \& T. A. Alfonso Sierra (eds.), Handbook on Law and Society in Latin America, Nueva York, Routledge, en prensa.

${ }^{50}$ Hinton, MeRCEDES, The State on the Streets. Police and Politics in Argentina and Brazil, Denver, Lynne Rienner, 2006, p. 3.
} 
tradicionales entre líderes políticos (autoridades gubernamentales) y la policía”. ${ }^{51}$ Si bien esta vinculación entre política y policía no es tan evidente en otros contextos, sin duda, reformar la policía es un proceso de redefinición del poder local y nacional.

La reforma policial incluye desafíos políticos, económicos, sociales, e incluso criminales, puesto que la policía, en lugar de ser la instancia más importante para resolver el crimen, se ha convertido en parte del problema. Aunque se han implementado varias reformas desde la década de 1990, el proceso democrático "ha traído solo una apariencia de policía democrática". ${ }^{52}$ La mayoría de los países en América Latina ha luchado por reformar instituciones, pero éstos enfrentan aún múltiples legados autoritarios.

En la región, los esfuerzos por sistematizar las iniciativas de reforma han sido diversos en los últimos años. ${ }^{53}$ Estos recuentos evidencian que se han realizado intentos de cambios estructurales o focalizados en prácticamente todos los países latinoamericanos. Muchos de ellos han enfrentado tres barreras principales: a) la violencia social intrínseca en la forma que los países se constituyeron y desarrollaron ha deslegitimado la importancia de la ley; b) la reacción interna de la policía a iniciativas consideradas "ajenas" a su cultura y críticas a su forma de organización interna, y c) el populismo punitivo que ha erosionado las iniciativas a largo plazo y deslegitimado los intentos de gobierno político de la reformas.

Los especialistas han presentado los intentos de reforma de múltiples formas. Prácticamente, todos coinciden en que deben asentarse sobre siete ejes: ${ }^{54}$ desmilitarización, despolitización, minimización funcional, diferenciación estructural, diferenciación funcional, descentralización espacial y modernización infraestructural. Adicionalmente, en el artículo, se proponen indicadores de reforma en la vinculación con otras instancias e instituciones ajenas a la policía.

En el marco de las tipologías definidas previamente, se observa que los factores considerados fundamentales tienen como principal derrotero el aumento

\footnotetext{
${ }^{51}$ Sain, Marcelo Fabián, El Leviatán azul. Policía y Politica en la Argentina, Buenos Aires, Siglo XXI, 2008, p. 49.

${ }^{52}$ Hinton, Mercedes, The State on the Streets. Police and Politics in Argentina and Brazil, Denver, Lynne Rienner, 2006, p. 191.

${ }^{53}$ Blattman, Christopher, Green, Donald, Ortega, Daniel y Tobón, Santiago, "Pre-Analysis Plan for 'The Impact of Hotspot Policing and Municipal Services on Crime: Experimental Evidence from Bogotá'". [Consulta: 20 de octubre, 2017]. Disponible en: https://www.aas.jjay.cuny.edu/single-post/ENG-Blattman-etal-2016; FRüHLING, Hugo, "Recent police reform in Latin America", en Niels Uldriks (ed.), Policing Insecurity. Police reform, security and human rights in Latin America, Landham, Lexington, 2009, pp. 21-47,

${ }^{54}$ Sain, Marcelo Fabiàn, La reforma policial en América Latina: Una mirada crítica desde el progresismo, Buenos Aires, Prometeo Libros, 2010, p. 80.
} 
de la capacidad y efectividad institucional. Esto debido a que se pueden realizar serios procesos de descentralización o modernización infraestructural sin que ello implique mayores niveles de rendición de cuentas y transparencia. Así, las principales transformaciones se ubican entre procesos que pueden consolidar control civil efectivo o autonomía burocrática.

El artículo analiza las iniciativas desarrolladas, así como sus limitaciones, desde una perspectiva integral que se organiza en dos ejes: capacidad/efectividad y rendición de cuentas/integridad. Ambos ejes se dividen entre acciones internas y externas a la institución, para reforzar el reconocimiento de que las tareas de seguridad ciudadana no son únicamente responsabilidad de las instituciones policiales. De esta forma, se avanza en la identificación de aquellas iniciativas que tienden a aumentar el control civil, principal objetivo de cualquier iniciativa de reforma policial.

Tabla 1. Indicadores de reforma policial

\begin{tabular}{|c|c|c|}
\hline & Capacidad/efectividad & Rendición de cuentas/integridad \\
\hline Interno & $\begin{array}{l}\text { - Definición de misión y funciones } \\
\text { - Recursos humanos } \\
\text { - Infraestructura } \\
\text { - Equipamiento } \\
\text { - Modelo de gestión } \\
\text { - Estrategias de policiamiento } \\
\text { - Investigación y análisis criminal }\end{array}$ & $\begin{array}{l}\text { - } \text { Política de derechos humanos } \\
\text { - } \text { Códigos de ética } \\
\text { - Protocolos disciplinarios } \\
\text { - } \text { Rendición de cuentas } \\
\text { presupuestarias } \\
\text { - Rendición de cuentas de metas } \\
\text { institucionales } \\
\text { - Estrategias focalizadas de } \\
\text { entrenamiento y capacitación }\end{array}$ \\
\hline Externo & $\begin{array}{l}\text { Estrategias de coordinación } \\
\text { y cooperación con otras } \\
\text { instituciones de la justicia } \\
\text { criminal } \\
\text { - Estrategias de coordinación } \\
\text { y cooperación con otras } \\
\text { instituciones públicas y privadas }\end{array}$ & $\begin{array}{l}\text { - Mecanismos formales de } \\
\text { monitoreo } \\
\text { - Mecanismos informales de } \\
\text { monitoreo }\end{array}$ \\
\hline
\end{tabular}

Fuente: Elaboración propia, 2018.

La conformación de una policía democrática requiere que ésta represente los intereses de la comunidad, proteja los derechos humanos y evidencie prácticas de rendición de cuentas administrativas, así como de sus acciones cotidianas. ${ }^{55}$

\footnotetext{
55 Aitchison, Andy \& Blaustein, Jarret, "Policing for democracy or democratically responsive policing? Examining the limits of externally driven police reform", European Journal of Criminology, vol. 10, núm. 4, pp. 496-511.
} 
Pero también viene aparejada con la consolidación de un proceso de responsabilidad del gobierno civil sobre las mismas. Más allá de su capacidad de influencia y liderazgo en la toma de decisiones institucionales, debe contar con diversos mecanismos de control que incluyan al Poder Legislativo, los medios de comunicación y la ciudadanía en su conjunto.

\section{La capacidad y efectividad policial}

La capacidad policial se vincula directamente con su misión y funciones. Contrario a lo que propone la literatura, los procesos de desmilitarización de las fuerzas policiales son aún débiles. En múltiples países, como México y Uruguay, se han conformado instancias de respuesta al crimen utilizan simbología y formas de acción militarizada y, además, fortalecen procesos de cambio doctrinal y formación. Este proceso va de la mano de una clara militarización de la seguridad pública, marcada por la activa participación de las Fuerzas Armadas en tareas de control, vigilancia, e incluso prevención. ${ }^{56}$

En México, se aprobó recientemente una propuesta de ley que establece los parámetros de participación de los militares en seguridad pública. Adicionalmente, si bien Carabineros de Chile pasó a depender del Ministerio del Interior y Seguridad Pública en el año 2011, dejando su anterior dependencia del Ministerio de Defensa, aún conserva mecanismos de formación y estructuración institucional de corte militarizado. Todavía es una incógnita si, como parte del proceso de post conflicto en Colombia, la Policía Nacional pasará a depender de un ministerio civil y dejará el ámbito de la Defensa Nacional.

En las últimas dos décadas, las instituciones policiales han consolidado un modelo de trabajo que tiende a aumentar las funciones, dispersando el foco de la prevención y el control del delito. Así, por ejemplo, muchos países están encargados de la regulación de la industria privada o del desarrollo de programas de vigilancia con tecnología, más allá del traslado de personas privadas de libertad, el cuidado de eventos masivos, la protección de altos dignatarios, la difusión de programas, o la capacitación de niños y jóvenes. Las reformas implementadas más que racionalizar sus funciones las han expandido, principalmente, como mecanismo para resolver la ansiedad ciudadana. ${ }^{57}$

La calidad del recurso humano policial es posiblemente el principal talón de Aquiles institucional. A inicios de los noventa, la mayoría de los policías no

\footnotetext{
${ }^{56}$ Diamint, Rut, "A new militarism in Latin America", Journal of Democracy, vol. 26, núm. 4, pp. 155-168.

${ }^{57}$ Dammert, Lucia y Salazar, Felipe, ¿Duros con el delito? Populismo e inseguridad en América Latina, Santiago de Chile, Flacso, 2009.
} 
contaban con requisitos básicos de educación formal ni eran capacitados en las mejores estrategias para administrar la institución o controlar el delito. De hecho, en diversos países ha quedado documentado el maltrato cotidiano de los ciudadanos hacia funcionarios policiales. ${ }^{58}$

Esta situación ha cambiado, por ejemplo, a partir del año 2016 en Uruguay, el requisito para ingresar a la policía nacional pasó de ser la primaria completa a la educación secundaria completa. Este requisito ya se solicita en prácticamente todas las instituciones de la región. Si bien el nivel educativo no necesariamente predice menores niveles de corrupción, sí aporta a la capacidad de implementar nuevos enfoques de trabajo policial..$^{59}$ Por ello, el terreno debería estar mucho más fértil para procesos de transformación institucional.

Los cambios en los procesos formativos han sido más lentos. Diversas instituciones carecen de la vinculación necesaria con centros de formación civiles que puedan fortalecer la formación policial y, más bien, tienden a reproducir los mecanismos de formación tradicionales. Países como México, Honduras, El Salvador, Guatemala y Paraguay han realizado cambios en el contenido, pero aún se acotan a la generación de una nueva perspectiva del trabajo policial.

En Colombia el proceso ha sido diferente. Se estima que la inversión en formación policial para focalizar y priorizar problemas trajo una reducción de delitos entre $19 \%$ y $34 \% .{ }^{60}$ Si bien la preocupación institucional por modernizar los procesos de formación viene desde inicios de los noventa, en la actualidad, el contexto de postconflicto instala nuevos desafíos institucionales. Como afirman Bulla y Guarin, el modelo nacional de vigilancia comunitaria por cuadrantes de la Policía Nacional "ha servido para aumentar y fortalecer las capacidades profesionales e institucionales para entender e intervenir el delito, sin embargo, en lugar de ser un catalizador del cambio institucional, puede servir como un dispositivo para mantener el statu quo". ${ }^{61}$

En Uruguay, parte del proceso de transformación de la institución policial ha incluido una redefinición completa de la malla. Se han adherido nuevos profesores no vinculados con la institución policial y se ha trazado el camino hacia la unificación del escalafón, con el fin de acceder a un sistema único de formación. A pesar de que algunos casos son diferentes, la norma son las

\footnotetext{
${ }^{58}$ Azaola, ElenA, Imagen y autoimagen de la policía de la ciudad de México, México, Ediciones Coyoacán, 2006.

59 Mckenna, Joseph y Pollock, Jorcelyn, "Law Enforcement Officers in Schools: An Analysis of Ethical Issues", Criminal Justice Ethics, vol. 33, núm. 3, pp. 163-184.

${ }^{60}$ Mejia, Daniel, Ortega, Daniel y Garcia, José Francisco, "Police Reform, Training and Crime: Experimental evidence from Colombia's Plan Cuadrantes", documento de trabajo, Caracas, CAF, 2013.

${ }^{61}$ Bulla, Patricia y Guarin, Sergio, Formación policial y seguridad ciudadana ¿Cómo mejorar el servicio de policía?, Bogotá, FES, 2015, p. 4.
} 
transformaciones desarrolladas con baja presencia y liderazgo civil, las cuales consolidan altos niveles de autonomía burocrática.

Otro de los pilares de las iniciativas de cambio es la modernización de la infraestructura y el equipamiento policial. En el caso de Ecuador, se estima que en la última década se invirtieron más de 830 millones de dólares. Ello incidió en la reducción de la tasa de homicidios, la cual pasó de 18, en el año 2008, a 5.7, en 2016. Así, se convirtió en la más baja de los últimos 30 años. La tendencia se confirma en todos los países, la inversión ha aumentado sin que ello vaya de la mano con procesos que evalúen su efectividad.

La inversión es también evidente en la adquisición de nuevas tecnologías que deberían permitir un control del delito más efectivo. Cámaras de televigilancia, drones, sistemas de escuchas telefónicas, lectores biométricos e identificadores de vehículos son algunas de las compras que los distintos gobiernos comunican por medios masivos para mostrar el progreso de la estrategia. La evaluación de su utilidad e impacto es prácticamente nula.

Una de las áreas donde se empiezan a evidenciar algunos cambios es en la definición de estrategias de trabajo policial. A inicios de la década pasada, se instaló el concepto de policía comunitaria como estrategia prioritaria para enfrentar los problemas de seguridad y convivencia. Sin embargo, los resultados no fueron alentadores. ${ }^{62}$ El cambio de filosofía en la vinculación institucional con la comunidad es un desafío pendiente y en la mayoría de los países de la región, si bien se consolidaron iniciativas focalizadas de policía comunitaria, las mismas respondían principalmente a pilotos de patrullaje en zonas turísticas o de baja intensidad del crimen. Así, mucho de lo que se llamó policía comunitaria dista significativamente de su conceptualización en Estados Unidos o Europa.

Otro concepto que rápidamente se trasladó de la criminología norteamericana hacia el sur del continente son los puntos calientes (hot spots) como eje de organización del trabajo policial. Al igual que en Estados Unidos, en América Latina, 50\% de los crímenes se concentran entre 3\% y 7.5\% de los segmentos de calle. ${ }^{63}$ Por ende, la localización de personal policial y la definición de patrullaje en esas zonas debería traer resultados en el combate al crimen. Diversas evaluaciones de impacto han mostrado resultados interesantes en el caso de

\footnotetext{
62 Riccio, Vicente, Ruediger, Marco Aurelo, Ross, Steven Dutt \& Skogan, Wesley, "Community policing in the Favelas of Rio de Janeiro", Police Practice and Research: An International Journal, vol. 14, núm. 4, pp. 308-318. WIISON, DAVID, Parks, Roger \& Mastrofski, Stephen, "The impact of police reform on communities of Trinidad and Tobago", Journal of Experimental Criminology, núm. 7, pp. 375-405.

${ }^{63}$ Jaitman, LaURA \& AJzenman, Nicolás, Crime concentration and hot spot dynamics in Latin America, BID, Working Paper Series \#699, 2016.
} 
Bogotá, Medellín y Uruguay, pero aún se encuentran en escala pequeña de implementación y en pocas localidades o barrios.

Finalmente, en aquellos territorios de alta peligrosidad o presencia del crimen organizado, se han desarrollado diversas iniciativas. Entre las más conocidas están las Unidades de Policía Pacificadora (UPP) en Brasil. Éstas buscaron disminuir los niveles de homicidio en las principales favelas de Río de Janeiro, mediante un aumento de la presencia policial en el territorio para disminuir los enfrentamientos letales. ${ }^{64} \mathrm{Si}$ bien los resultados en términos de disminuir los homicidios fueron limitados, el programa tuvo un impacto en disminuir los asesinatos por parte de la policía. ${ }^{65}$

En la última década, también se presentan algunos cambios respecto a las iniciativas externas que tienen como principal objetivo la coordinación y colaboración con otras instituciones para el aumento de la efectividad policial. En primer lugar, las instituciones policiales han reconocido la necesidad de colaborar con gobiernos locales que, muchas veces, desarrollan mecanismos de patrullaje y vigilancia mejor dotados de personal e infraestructura. Tal es el caso de algunos municipios del Perú con programas de Serenazgo, y de Chile con programas de vigilancia comunitaria.

No hay evidencias claras sobre la efectividad y articulación cotidiana de esta colaboración, pero, sin duda, es un actor emergente que empieza a tener roles cada vez más relevantes en la seguridad a nivel local. De igual manera, se multiplican las organizaciones comunitarias de prevención del delito cuyos programas van desde la colocación de cámaras de videovigilancia, compra de alarmas comunitarias e instalación de cierres perimetrales, hasta la consolidación de esquemas de rondas de vecinos y patrullaje.

Si bien, en algunos casos, parte primordial de la iniciativa tiene como objetivo aumentar la efectividad del trabajo policial, en territorios marcados por la precariedad estas instancias sirven también para "vigilarlos". El reclamo ciudadano ha pasado del malestar a la acción, del rumor a las redes sociales, con múltiples denuncias ciudadanas que, prácticamente en vivo, muestran las deficiencias del accionar policial.

\footnotetext{
${ }^{64}$ Cano, Ignacio, Os donos do morro; uma avilacao exploratória do impacto das Unidades de Polícia Pacificadora (UPPS) no Rio de Janeiro, Rio de Janeiro, Relatorio do LAV-CAF, 2012. [Consulta: 21 de octubre, 2017]. Disponible en: http://www.lav.uerj.br/docs/rel/2012/RelatUPP.pdf

${ }^{65}$ Magaloni Beatriz, Franco, Edgar \& Melo, Vanessa, Killing in the Slums: An Impact Evaluation of Police Reform in Rio de Janeiro. [Consulta: 20 de octubre, 2017]. Disponible en: http://globalpoverty.stanford.edu/sites/default/files/ publications/556wp.pdf
} 
En el marco del sistema de justicia criminal, desde la implementación de la reforma procesal penal, el mayor desafío es la relación con los fiscales (Ministerio Público). Principalmente, ello se debe al rol activo y de liderazgo que tiene el fiscal en la investigación criminal. Esta situación ha traído múltiples complejidades que aún no han sido evaluadas en términos del impacto sobre la impunidad de los delitos, pero han afectado la gestión pública sobre la investigación criminal.

Finalmente, en las iniciativas de prevención del delito policial que se han desarrollado como parte de los paquetes de transformación policial en las últimas dos décadas, la colaboración con otros sectores de gobierno es escasa. ${ }^{66}$ Si bien se han desarrollado iniciativas y programas piloto en prevención -vinculados con temas de salud, educación, deporte, entre otras actividades- la mayoría se realizan de forma esporádica y no han sido evaluados para conocer su impacto en los factores de riesgo identificados como prioritarios.

Todo lo anterior permite afirmar que los avances son aún puntuales y la mayoría de las instituciones de policía de la región siguen realizando sus labores en el marco de formatos tradicionales, con altos niveles de autonomía y, al menos, desconocidos niveles de efectividad. Así, se confirma la preeminencia de un tipo de reforma que, paradójicamente, ha fortalecido la autonomía burocrática de las instituciones policiales.

\section{Rendición de cuentas e iniciativas de integridad}

Alta inversión pública, bajos niveles de conocimiento y un generalizado desgobierno de las instituciones son receta fundamental para la opacidad policial. Si bien en los últimos años se han dado avances en la materia, es evidente que los temas de integridad y legitimidad policial aún no están en el centro de la agenda de reformas policiales. Los casos exitosos de reforma y las iniciativas más puntuales de modernización institucional han puesto énfasis en la necesidad de aumentar la información pública sobre la criminalidad.

110 También la implementación de mecanismos de rendición de cuentas hacia el Estado y la sociedad se cuenta como una medida exitosa. ${ }^{67}$ Así lo evidencia Moncada, ${ }^{68}$ cuando analiza el caso de Bogotá con iniciativas como la revisión

\footnotetext{
${ }^{66}$ Tello, NeLIA, "Police reforms: the voice of police and residents in Mexico City", Policing and Society, vol. 22, núm. 1, pp. 14-27.

${ }^{67}$ SRUR, JoRGE, ¿Qué observan los que observan el delito? Pasado, presente y futuro de los observatorios del crimen y la violencia en América Latina y el Caribe. [Consulta: 20 de octubre, 2017]. Disponible en: https://publications.iadb.org/

${ }^{68}$ MonCADA, EduARDo, "Toward Democratic Policing in Colombia? Institutional Accountability through Lateral Reform",
} 
del código de conducta policial y el desarrollo de policía comunitaria en barrios donde el nivel de legitimidad policial era bajo. En los casos de México y Ecuador, se construyeron centros de comando y control que incluyen la gestión de los temas de seguridad, Plataforma México y Ecu911, respectivamente, pero estas iniciativas no implicaron mayores niveles de transparencia de la información.

Como parte de una agenda reformista en el eje de rendición de cuentas e integridad, se podrían considerar múltiples elementos, sin embargo, el presente artículo se concentra en la violencia policial y el presupuesto. Ambos cubren desde lo operativo hasta la gestión institucional y brindan luz sobre los altos grados de opacidad e ineficiencia institucional que permean las instituciones. Además, ambos se pueden enfrentar con relativa rapidez si se evidencia voluntad política y un efectivo gobierno de la policía.

Como se afirmó previamente, el nivel de violencia que utilizan las policías se mantiene como un serio problema de derechos humanos en la región. ${ }^{69}$ No sólo por cómo se enfrentan posibles situaciones delictuales, sino por la relación con la ciudadanía. El uso de la violencia genera impactos sustantivos en los niveles de confianza ciudadana.

Las respuestas institucionales en una primera etapa se vincularon con la elaboración de políticas de derechos humanos, cursos de formación policial y mecanismos de sensibilización. Sin embargo, continúa la presencia de incentivos adversos, la presión por resultados y una cultura de secretismo y violencia. Desde los falsos positivos en Colombia, hasta el uso indiscriminado de violencia en marchas callejeras en Chile, el uso excesivo de la fuerza es un problema transversal.

En el estudio de Osse y Cano, ${ }^{70}$ la gravedad del problema se confirma cuando, de los homicidios cometidos en El Salvador durante el 2015, 17\% tuvo como responsable a un policía. Mientras, en Jamaica en el 2014, este tipo de hechos llegó a 14\%. De igual forma, la magnitud del fenómeno en México se evidencia en el informe de Human Rights Watch, ${ }^{71}$ cuando establece que "la tortura continúa siendo extensamente practicada en México para obtener confesiones forzosas y extraer información".

\footnotetext{
Comparative Politics, vol. 41, núm. 4, pp. 431-449.

${ }^{69}$ Anneke, Osse \& CAno, Ignacio, "Police deadly use of firearms: an international comparison", The International Journal of Human Rights, vol. 21, núm. 5, pp. 629-649.

${ }^{70}$ AnNeKE, OSSE \& CANo, IGNACIO, "Police deadly use of firearms: an international comparison", The International Journal of Human Rights, vol. 21, núm. 5, pp. 629-649..

${ }^{71}$ Human Rights Watch, World Report 2014, Human Rights Watch. [Consulta: 21 de noviembre, 2017]. Disponible en: https://www.hrw.org/sites/default/files/world_report_download/wr2014_web.pdf
} 
En Brasil, la información de violencia policial presenta números de emergencia. Sólo en el año 2012, murieron 1890 personas durante operaciones policiales. En el 2015, en el estado de Río de Janeiro, se confirmaron 645 personas fallecidas en operativos policiales. Finalmente, en Venezuela, se estima que "la violencia policial no sólo no disminuye, sino que incluso podría incrementar el delito, la violencia y la inseguridad". ${ }^{72}$

A pesar de la gravedad del problema, las respuestas son aún limitadas. Si bien se han realizado inversiones sustanciales para mejorar la infraestructura educativa en los contenidos de formación y entrenamiento, no han sido transformados para hacerse cargo de los problemas de la cultura organizacional. Sin embargo, la capacitación es clave para disminuir el uso de armas en situaciones de riesgo. Así lo evidenció una intervención realizada en Argentina cuando, luego de participar en un curso de 45 horas, el porcentaje de oficiales que dijo estar de acuerdo con "arriesgar la vida para evitar un asalto disminuyó de 51 a 38\%". ${ }^{73}$

Las iniciativas de reforma policial que se han implementado en América Latina para enfrentar la cotidianidad de la violencia policial han tenido resultados adversos. En diversos países, se ha instalado una narrativa centrada en la necesidad de enfrentar con "fuerza" el crimen organizado, abriendo la puerta para la justificación al "gatillo fácil" en procedimientos cuya vinculación con organizaciones criminales está al menos en entredicho. Un segundo eje narrativo es la presunción de que las víctimas son "miembros del crimen organizado". Esta situación sólo en contados casos se confirma con base en procesos de investigación policial posteriores. Finalmente, la voluntad política para enfrentar rasgos estructurales de la labor policial se disipa con relativa facilidad, cuando frente al control del uso de violencia se esgrime "garantismo" o "mano blanda" contra el delito.

Las instancias de control interno y externo juegan roles secundarios y en limitadas ocasiones enfrentan esta problemática. Así, se fortalecen el uso de la fuerza y la generalizada percepción de impunidad. Los códigos de disciplina, si bien modernizados, se enfrentan a situaciones donde la evidencia no se recolecta con detalle. Además, las alteraciones del hecho del suceso son cotidianas y el desarrollo de pericias apropiadas permiten altos niveles de impunidad. El control externo es también débil. Llama la atención que los mecanismos de control por parte del Legislativo son casi inexistentes y que la preocupación

\footnotetext{
72 Antillano, Andrés, "¿Qué conocemos de la violencia policial en Venezuela? Las investigaciones e hipótesis sobre el uso de la fuerza física por la policia", Espacio Abierto, vol. 19, núm. 2, pp. 331-345.

${ }^{73}$ CAF, Programa sobre uso de la fuerza y empleo de armas de fuego. Resumen de evaluación de impacto. [Consulta: 20 de octubre, 2017] Disponible en: http://scioteca.caf.com/handle/123456789/455
} 
de las últimas dos décadas ha estado centrada en aprobar leyes con mayores castigos y entregar mayores facultades al accionar policial.

Un segundo elemento que permite analizar los procesos de cambio en las instituciones policiales es la rendición de cuentas sobre la información presupuestaria. Como se mencionó previamente, la inversión pública en las instituciones policiales es sustancial y crece anualmente en todos los países de la región. Así, un estudio sobre Centroamérica y México evidenció un incremento de 131\% en el gasto en Ministerios de Seguridad en el periodo 2006-2011. Por otro lado, la información de la Policía Nacional de El Salvador muestra un incremento presupuestario para el rubro salarios, de 172 a 248 millones de colones en el periodo 2009-2015. Finalmente, en Chile, el presupuesto de Carabineros en el 2016 alcanzó una cifra muy similar a la de las tres ramas de las Fuerzas Armadas en su conjunto.

A pesar del aumento presupuestario, un porcentaje muy alto de éste se destina a salarios. En consecuencia, los desarrollos de infraestructura, tecnología y soporte de gestión quedan relegados a un segundo plano de la inversión. Esto lleva a un peligroso círculo, donde la incapacidad de gestión se vincula con limitaciones en evaluar y monitorear las iniciativas. A su vez, incrementan las acciones con presencia en medios, pero éstas no necesariamente tienen capacidad de impacto.

A pesar de que los salarios policiales han subido en América Latina, los procesos de corrupción individual, grupal e institucional están lejos de desaparecer. La presencia de corrupción remite nuevamente a las limitadas capacidades de control interno y externo. Esto se ha vinculado en la literatura internacional con una institucionalidad estatal débil que no logra implantar el Estado de derecho. ${ }^{74}$ Los escándalos de corrupción que se conocieron como "la comunidad del anillo" en la Policía Nacional de Colombia -que incluía una posible red de prostitución masculina vinculada con tráfico de influencias-,así como el de Carabineros de Chile, demuestran que la falta de control externo es elemento clave para el desarrollo de actividades ilícitas.

La transparencia presupuestaria -saber efectivamente cuánto dinero se invierte en la institución y cómo se gasta- debería ser un elemento básico en cualquier proceso de reforma policial. Lamentablemente, son pocas las iniciativas que han tenido éxito en esta perspectiva. Cabe destacar el rol que múltiples instituciones de la sociedad civil, organizaciones no gubernamentales, e incluso organismos internacionales han jugado al tratar de aumentar la

\footnotetext{
${ }^{74}$ Arias Desmond, Enrique \& Goldstein, Daniel, Violent Democracies in Latin America, Durham, Duke University Press, 2010.
} 
transparencia y rendición de cuentas presupuestarias. Sin embargo, los resultados son limitados.

Todo lo anterior confirma que las iniciativas de reforma de las policías latinoamericanas en torno a rendición de cuentas e integridad han avanzado en la generación de marcos, arquitectura jurídica o incluso protocolos de intervención. Sin embargo, las prácticas de opacidad, corrupción y bajos niveles de control interno y externo siguen siendo elementos cotidianos en el accionar policial. Los cambios se enmarcan en los cuadrantes de autonomía burocrática o disfuncional, dependiendo de si se logran mejores mecanismos para el diseño e implementación de iniciativas destinadas a mejorar la efectividad policial. De tal modo, se dejan atrás los posibles caminos hacia el desarrollo de control civil efectivo e incluso reactivo.

\section{Conclusiones}

Reformar la policía en América Latina es una tarea eminentemente política. Del mismo modo en que, con el regreso a la democracia, uno de los primeros objetivos fue restablecer una división clara, donde los militares no tenían espacio de participación política, en la actualidad, el desafío latinoamericano pasa por construir instituciones policiales efectivas, profesionales, despolitizadas y desmilitarizadas.

La voluntad de transformación se limita por la percepción de algunos gobiernos y actores políticos, pues éstos perciben que los cambios pueden desestabilizar la institución policial y, por ende, traer serias consecuencias a la gobernabilidad. Además, la falta de voluntad política, en muchos casos, se asienta sobre esquemas de corrupción político-policial, por objetivos complementarios.

En Argentina, Hathazy ${ }^{75}$ resume los problemas de la reforma de la policía cuando afirma que "el personalismo y la debilidad institucional del sistema de partidos argentinos se han transmitido fácilmente a la burocracia, produciendo discontinuidad de las reformas y cambios muy limitados”. También, la politi-

114 zación de las fuerzas policiales, utilizadas como "guardias" de la administración, es un proceso continuo que aumenta la impunidad, disminuye el control interno, limita la transparencia y erosiona las iniciativas de reformas.

La trayectoria de las reformas policiales tiene un estrecho vínculo con las estructuras políticas y burocráticas nacionales no sólo en Argentina, sino en toda

\footnotetext{
${ }^{75}$ HathazY, Paul, "Fighting for a democratic police: Politics, Experts and Bureaucrats in the transformation of the police in post-authoritarian Chile and Argentina", Comparative Sociology, núm. 12, p. 34.
} 
la región. Ahora bien, no todo el panorama policial en la región es gris. Los avances son sustanciales en el eje que hemos llamado capacidad/efectividad, pues se han modernizado protocolos; han aumentado los niveles de educación y formación; se han definido nuestras estrategias de trabajo policial y, en algunos casos, se ha construido evidencia suficiente para identificarlos como exitosos.

En una mirada longitudinal, los cambios experimentados en la mayoría de las instituciones, durante las últimas dos décadas, son evidentes. Éstos han afectado la forma en que se conceptualiza la seguridad desde lo gubernamental y desde la ciudadanía.

En el eje integridad/rendición de cuentas los avances son mucho más cosméticos que estructurales. La discrecionalidad y opacidad del trabajo policial es aún significativa y no se ha podido enfrentar de forma estructural en prácticamente ninguna policía de la región. En algunos casos, ello se debe a la incapacidad del gobierno civil para avanzar con mecanismos serios de rendición de cuentas. En otros, es causa de la debilidad del gobierno civil para asumir los temas de seguridad pública $\mathrm{y}$, en paralelo, la fortaleza policial para impedir procesos de cambio.

Al afirmar que la reforma policial es una tarea política, no se propone dejar de lado los aprendizajes de la literatura internacional sobre "lo que sirve y no sirve" en las estrategias y tácticas policiales. Por el contrario, se establece la necesidad de reconocer el rol político que han jugado las policías en los últimos veinte años, su consolidación como vértices en la vinculación entre la ciudadanía y los actores políticos locales y la relación que cotidianamente se establece con el crimen en sus diversas manifestaciones. Salir de la trampa de la autonomía burocrática, que entrega poder y responsabilidad a las policías a cambio de una sensación ciudadana de acción política, debe ser el camino hacia el control civil efectivo. Reformar sin gobernar es un camino que lleva a la corrupción, la ineficiencia y la violencia.

\section{Referencias}

Aitchison, Andy \& Blaustein, Jarret, "Policing for democracy or democratically responsive policing? Examining the limits of externally driven police reform", European Journal of Criminology, vol. 10, núm. 4.

Albright, DAVID, "Comparative Conceptualization of Civil-Military Relations", World Politics, vol. 32, núm. 4.

Antillano, Andrés, "Crimen y castigo en la revolución bolivariana", Cuestiones de Sociología, núm. 10. [Consulta: 26 de noviembre, 2017]. Disponible en: http:// www.cuestionessociologia.fahce.unlp.edu.ar/article/view/CSn10a19/6096 
Antillano, Andrés, “¿Qué conocemos de la violencia policial en Venezuela? Las investigaciones e hipótesis sobre el uso de la fuerza física por la policía”, Espacio Abierto, vol. 19, núm. 2.

Anneke, Osse \& Cano, Ignacio, "Police deadly use of firearms: an international comparison”, The International Journal of Human Rights, vol. 21, núm. 5.

Arias Desmond, Enrique y Goldstein, Daniel, Violent Democracies in Latin America, Durham, Duke University Press, 2010.

Arias, Patricia, Rosada-Granados, Héctor y Saín, Marcelo Fabián, Reformas policiales en América Latina. Principios y lineamientos progresistas, Bogotá, FES, 2012.

Azaola, Elena, Imagen y autoimagen de la policía de la ciudad de México, México, Ediciones Coyoacán, 2006.

Blattman, Christopher, Green, Donald, Ortega, Daniel y Tobón, Santiago, "Pre-Analysis Plan for 'The Impact of Hotspot Policing and Municipal Services on Crime: Experimental Evidence from Bogotá”. [Consulta: 20 de octubre, 2017]. Disponible en: https://www.aas.jjay.cuny.edu/single-post/ENG-Blattman-etal-2016

Bobea, LliLIAN, "The emergence of the democratic citizen security policy in the Dominican Republic”, Policing and Society, vol. 22, núm. 1.

BRINKS, DANIEL, The judicial response to police killings in Latin America: Inequality and the rule of law, Nueva York, Cambridge University Press, 2016.

Brogden, Michael, The police: Autonomy and consent, London, Academic Press, 1982.

Bruneau, Thomas, Dammert, Lucía y Skinner, Elizabeth, Maras: Gang Violence and Security in Central America, Austin, University of Texas Press, 2011.

Bruneau, Thomas, "Civilians and the Military in Latin America: The Absence of Incentives”, Latin American Politics and Society, vol. 55, núm. 4.

Bulla, Patricia y Guarin, Sergio, Formación policial y seguridad ciudadana ¿Cómo mejorar el servicio de policía?, Bogotá, FEs, 2015.

CAF, Programa sobre uso de la fuerza y empleo de armas de fuego. Resumen de evaluación de impacto. [Consulta: 20 de octubre, 2017] Disponible en: http://scioteca. caf.com/handle/123456789/455

CAno, Ignacio, Os donos do morro; uma avilacao exploratória do impacto das Unidades de Polícia Pacificadora (UPPS) no Rio de Janeiro, Rio de Janeiro, Relatorio do lav-caf, 2012. [Consulta: 21 de octubre, 2017]. Disponible en: http://www.lav. uerj.br/docs/rel/2012/RelatUPP.pdf

CARroll, Rory, "Deadly force: Venezuela's police have become a law unto themselves", The Guardian. [Consulta: 28 de octubre, 2017]. Disponible en: https://www.theguardian.com/world/2009/sep/06/venezuela-police-law-themselves

Corbacho, Ana, Julia, Philipp y Ruiz-Vega, Mauricio, “Crime and Erosion of trust: Evidence for Latin America”, World Development, núm. 70.

Crisp \& Datafolha, Pesquisa Nacional de Victimizaçao 2013. Sumário Executivo. [Consulta: 27 de octubre, 2017]. Disponible en: http://www.interconect.com.br/ clientes/pontes/blog/pnv.pdf 
Cruz, José Miguel, "Police Misconduct and Political Legitimacy in Central America”, Journal of Latin American Studies, vol. 47, núm. 2.

DAMmert, LucíA, “Challenges of police reform in Latin America”, en R. Sieder, K. Ansolabehere \&t T. A. Alfonso Sierra (eds.), Handbook on Law and Society in Latin America, Nueva York, Routledge, en prensa.

DAmmert, Lucía, “The Peruvian Perfect Storm: State Fragility, Corruption and Organized Crime”, en H. Kassab \& Jonathan Rosen (eds.), Fragile States in the Americas, Washington, Lexington Books, 2016.

DAmmert, LuCíA, Fear and Crime in Latin America: Redefining State-Society Relations, Nueva York, Routledge, 2012.

Dammert, Lucía y Salazar, Felipe, ¿Duros con el delito? Populismo e inseguridad en América Latina, Santiago de Chile, Flacso, 2009.

Diamint, Rut, “A new militarism in Latin America”, Journal of Democracy, vol. 26, núm. 4.

Dudley, Steven, "How drug trafficking operates, corrupts in Central America", Insight Crime, julio, 2016. [Consulta: 17 de septiembre, 2017]. Disponible en: http://www. insightcrime.org/news-analysis/how-drug-trafficking-operates-corrupts-incentral-america

Feaver, Peter, Armed Servants: Agency, Oversight, and Civil-Military Relations, Boston, Harvard University Press, 2003.

Feaver, Peter, "The civil-military problematique: Huntington, Janowitz, and the question of civilian control", Armed Forces \& Society, vol. 23, núm. 2, 1996, pp. 149-178.

FrüHling, Hugo, "Recent police reform in Latin America”, en Niels Uldriks (ed.), Policing Insecurity. Police reform, security and human rights in Latin America, Landham, Lexington, 2009.

Glanc, LAURA, "Caught between soldiers and police officers: police violence in contemporary Argentina”, Policing and Society, vol. 24, núm. 4.

Hathazy, Paul, "Fighting for a democratic police: Politics, Experts and Bureaucrats in the transformation of the police in post-authoritarian Chile and Argentina", Comparative Sociology, núm. 12.

Hinton, Mercedes, The State on the Streets. Police and Politics in Argentina and Brazil, Denver, Lynne Rienner, 2006.

Human Rights Watch, “World Report 2016”, Human Rights Watch. [Consulta: 20 de noviembre, 2017]. Disponible en: https://www.hrw.org/sites/default/files/world_ report download/wr2016 web.pdf

Human Rights Watch, World Report 2014, Human Rights Watch. [Consulta: 21 de noviembre, 2017]. Disponible en: https://www.hrw.org/sites/default/files/world report_download/wr2014_web.pdf

Huntington, SAMUEL, The soldier and the State, Boston, Vintage Books, 1957.

Huntington, Samuel, The Strategic imperative: New policies for American security, Massachusets, Ballinger Publishing House, 1982. 
IgARAPÉ, “Homicide Monitor”, Igarapé Institute. [Consulta: 20 de noviembre, 2017]. Disponible en: https://homicide.igarape.org.br/

JAITMAN, LAURA, The costs of crime and violence: New evidence and insights in Latin America and the Caribbean. [Consulta: 18 de octubre, 2017]. Disponible en: https://publications.iadb.org/handle/11319/8133\#sthash.VUbnzmII.pdf

Jaitman, Laura \& Ajzenman, Nicolás, Crime concentration and hot spot dynamics in Latin America, bid, Working Paper Series \#699, 2016.

JANOWITZ, MoRris, The new military changing patterns of organization, Bussel Saga Foundation, New York, 1964.

JANowitz, Morris, Military institutions and coercion in the developing nations, Chicago, The University of Chicago Press, Chicago, 1977.

Lagos, Marta y Dammert, Lucía, La Seguridad Ciudadana: El Problema Principal De América. [Consulta: 27 de octubre, 2017]. Disponible en: http://www.latinobarometro.org/documentos/LATBD_La_seguridad_ciudadana.pdf

Latin American Public Opinion Project, “The AmericasBarometer”, Vanderbilt University.

[Consulta: 20 de noviembre, 2017]. Disponible en: www.LapopSurveys.org

Loveman, Brian, For La Patria: Politics and the Armed Forces America, Wilmington, Scholarly, 1999.

Magaloni Beatriz, Franco, Edgar \& Melo, Vanessa, Killing in the Slums: An Impact Evaluation of Police Reform in Rio de Janeiro. [Consulta: 20 de octubre, 2017]. Disponible en: http://globalpoverty.stanford.edu/sites/default/files/publications/556wp.pdf

Mckenna, Joseph y Pollock, Joycelyn, "Law Enforcement Officers in Schools: An Analysis of Ethical Issues”, Criminal Justice Ethics, vol. 33, núm. 3.

Mejía, Daniel, Ortega, Daniel y García, José Francisco, "Police Reform, Training and Crime: Experimental evidence from Colombia's Plan Cuadrantes”, documento de trabajo, Caracas, cAF, 2013.

Moncada, Eduardo, "Toward Democratic Policing in Colombia? Institutional Accountability through Lateral Reform”, Comparative Politics, vol. 41, núm. 4.

Mota-Prado, Mariana, Trebilcock, Michael y Hartford, Patrick, "Police Reform in Violent Democracies in Latin America”, Hague Journal on the Rule of Law, vol. 4, núm. 2.

PÁSARA, LuIs, “International support for justice reform: Is it worthwhile?”, Mexican Law Review, vol. 6, núm. 1.

Perez Liñan, Anibal \& Smith, Noah, "Democratic quality and democratic survival”, en Luca Tomini y Giulia Sandri (eds.), Challenges of Democracy in the 21st Century. Concepts, Methods, Causality and the Quality of Democracy, Nueva York, Routledge, 2018.

Pion-Berlin, David y Trinkunas, Harold, "Democratization, Social Crisis, and the Impact of Military Domestic Roles in Latin America”, Journal of Political and Military Sociology, vol. 33, núm. 1. 
Pion-Berlin, David y Martinez, Rafael, Soldiers, politicians, and civilians: Reforming civil-military relation in Democratic Latin America, Cambridge, Cambridge University Press, 2017.

Reiner, Robert, The politics of the police, Hemel Hempstead, Harvester Wheatsheaf, 1992.

Riccio, Vicente, Ruediger, Marco Aurelio, Ross, Steven Dutt \& Skogan, Wesley, “Community policing in the Favelas of Rio de Janeiro", Police Practice and Research: An International Journal, vol. 14, núm. 4.

Ruiz Torres, Miguel y Azadla Garrido, Elena, “Cuadrar el delito: Corrupción institucional y participación de policías en el secuestro en México”, Perfiles Latinoamericanos, vol. 22, num. 4.

Saín, Marcelo Fabián, El Leviatán azul. Policia y Política en la Argentina, Buenos Aires, Siglo XXI, 2008.

Saín, Marcelo Fabián, "Es la política, estúpido. El Gobierno Federal frente a la reforma policial en Argentina”, Comunes, núm. 1.

Seri, Guillermina, Seguridad: Crime, Police Power, and Democracy in Argentina, Nueva York, Continuum International Publishing Group, 2012.

Sharp, Douglas, "Who needs theories in policing? An introduction to a special issue on policing”, The Howard Journal, vol. 44, núm. 5.

SLANSKY, DAVID, "The promise and the perils of police professionalism", en Jennifer Brown (ed.), The future of policing, Nueva York, Routledge, 2014.

Sozzo, MÁximo, "Policing after Dictatorship in South America", en Ben Bradford, Beatrice Jauregui, Ian Loader, Jonny Steinberg (eds.), The sage Handook of Gobal Policing, Londres, SAGE, 2016.

SRUR, JoRge, ¿Qué observan los que observan el delito? Pasado, presente y futuro de los observatorios del crimen y la violencia en América Latina y el Caribe. [Consulta: 20 de octubre, 2017]. Disponible en: https://publications.iadb.org/

Stepan, Alfred, Rethinking Military Politics: Brazil and the Southern Cone, Princeton, Princeton University Press, 1988.

Tello, Nelia, "Police reforms: the voice of police and residents in Mexico City", Policing and Society, vol. 22, núm. 1.

Transparencia Internacional, Corruption Perceptions Index 2015, Transparencia Internacional. [Consulta: 10 de septiembre, 2017]. Disponible en: http://www.transparency.org/cpi2015

Trinkunas, Harold, "Crafting Civilian Control in Emerging Democracies: Argentina and Venezuela", Journal of Interamerican Studies and World Affairs, vol. 42, núm. 3.

Ungar, Mark, "The Rot Within: Security and Corruption in Latin America”, Social Research: An International Quarterly, vol. 80, núm. 4.

Ungar, Mark, "The Privatization of Citizen Security in Latin America: From Elite Guards to Neighborhood Vigilantes”, Social Justice, núm. 34. 
unodc, Transnational organized crime in Central America and the Caribbean. A threat assessment, Viena, unODC, 2012.

Wilson, David, Parks, Roger \& Mastrofski, Stephen, "The impact of police reform on communities of Trinidad and Tobago", Journal of Experimental Criminology, núm. 7. 